\title{
The Efficacy of Ketogenic Diet and Associated Hypoglycemia as an Adjuvant Therapy for High-Grade Gliomas: A Review of the Literature
}

\author{
Kunal Varshneya ${ }^{1}$, Christine Carico ${ }^{1}$, Alicia Ortega ${ }^{1}$, Chirag G. Patil ${ }^{2}$ \\ 1. Center for Neurosurgical Outcomes Research, Maxine Dunitz Neurosurgical Institute, Cedars-Sinai \\ Medical Center 2. Cedars-Sinai Medical Center
}

$\square$ Corresponding author: Kunal Varshneya, kvarshne@usc.edu

Disclosures can be found in Additional Information at the end of the article

\section{Abstract}

Background: A high-fat, low-carbohydrate diet, often referred to as a ketogenic diet (KD), has been suggested to reduce frequency and severity of chronic pediatric and adult seizures. A hypoglycemic state, perpetuated by administration of a $\mathrm{KD}$, has been hypothesized as a potential aid to the current standard treatments of high-grade gliomas.

Methods: To understand the effectiveness of the ketogenic diet as a therapy for malignant gliomas, studies analyzing components of a KD were reviewed. Both preclinical and clinical studies were included. The keywords "ketogenic diet, GBM, malignant glioma, hyperglycemia, hypoglycemia" were utilized to search for both abstracts and full articles in English. Overall, 39 articles were found and included in this review.

Results: Studies in animal models showed that a KD is able to control tumor growth and increase overall survival. Other pre-clinical studies have suggested that a KD sustains an environment in which tumors respond better to standard treatments, such as chemoradiation. In human cohorts, the KD was well tolerated. Quality of life was improved, compared to a standard, non-calorie or carbohydrate restricted diet. Hyperglycemia was independently associated with diminished survival.

Conclusion: Recent clinical findings have demonstrated that induced hypoglycemia and ketogenic diet are tolerable and can potentially be an adjuvant to standard treatments, such as surgery and chemoradiation. Other findings have advocated for KD as a malignant cell growth inhibitor, and indicate that further studies analyzing larger cohorts of GBM patients treated with a KD are needed to determine the breadth of impact a KD can have on GBM treatment.

Received 02/07/2015

Review began 02/09/2015

Review ended 02/27/2015

Published 02/27/2015

C Copyright 2015

Varshneya et al. This is an open access article distributed under the terms of the Creative Commons Attribution License CC-BY 3.0., which permits unrestricted use, distribution, and reproduction in any medium, provided the original author and source are credited.
Categories: Neurosurgery

Keywords: high-grade glioma, ketogenic diet, hypoglycemia, neurosurgery, hyperglycemia, glioblastoma

\section{Introduction And Background}

Glioblastoma (GBM) is the most prevalent and aggressive primary intracranial tumor. Although relatively rare, with an occurrence rate of 2 out of 100,000 people, GBMs account for over $82 \%$ of all malignant gliomas [1]. Despite multimodal treatment, including radiation and 
chemotherapy following aggressive surgical resection, the prognosis is still poor with a median survival of 13-15 months post-diagnosis [2-3]. Similar to GBMs, traditional treatment of anaplastic astrocytomas (AAs) includes primary resection followed by radiation and chemotherapy [4-5]. Additionally, given that GBMs and AAs are often located in the eloquent cortex and have innate abilities to proliferate extensively, recurrence often occurs approximately 32-36 weeks after initial treatment [1]. Radiation and chemotherapy have been shown to increase progression-free survival (PFS); however, overall survival (OS) for GBM patients remains poor with only $15-20 \%$ of patients surviving longer than three years [6]. Recent basic laboratory studies have demonstrated that alternative treatments, such as progesterone therapy and restrictive diets, may inhibit angiogenic molecular pathways in glial cells, attenuating malignant glioma growth [7-10].

A high-fat, low-carbohydrate diet, often referred to as a ketogenic diet (KD), has been suggested to reduce frequency and severity of chronic pediatric and adult seizures [11-14]. Recent studies have demonstrated that a calorically-restricted diet administered to mice infused with a malignant mouse astrocytoma (CT-2A) or a human glioma (U87-MG) was effective in decreasing vascularity, increasing programmed cell death, and was associated with diminished levels of insulin-like growth factors [15]. The effectiveness of calorie restriction or a ketogenic diet can be understood through analysis of its biochemistry. A landmark study by Nobel laureate Otto Warburg demonstrated neoplastic metabolic dependence on aerobic glycolysis for energy production [16]. A consumed fat molecule (triacylglycerol) is catabolized into free fatty acids and eventually Acetyl-CoA. If increased fatty acid oxidation elevates the levels of Acetyl-CoA to surpass the capacity of the citric acid cycle, excessive levels of ketone bodies accumulate ( $\beta$-hydroxybutyrate (BHB) and acetoacetate (ACA)) [8, 17-18]. Normal neurons and glial cells are able to metabolize BHB and ACA; however, neoplastic cells appear less able to utilize these sources for energy derivation. Cancer (CP1) cells also have markedly elevated levels of reactive oxygen species (ROS) that have been associated with angiogenesis and cell proliferation through mediation of vascular endothelial growth factor (VEGF) and hypoxia inducible factor 1 (HIF-1). Ketone bodies have been linked to ROS reduction in vivo [19]. Due to tumor cells' metabolic dependence on glucose and glutamate, elevated levels of ketone bodies in the intracranial region diminish glycolytic levels and inhibit angiogenesis [7, 17, 2021].

\section{Review}

\section{Methods}

To understand the effectiveness of the ketogenic diet as a therapy for malignant gliomas, studies analyzing components of a KD and its implementation in both preclinical and clinical studies were reviewed. The focus of this review was on the anti-tumor effects of a KD in highgrade gliomas. A literature review was conducted and articles from 1976 to 2014 in PubMed were reviewed for their relation to efficacy of the ketogenic diet as alternative therapy for glioma. Both preclinical and clinical studies were included. The keywords "ketogenic diet," "GBM," "malignant glioma," "hyperglycemia," and "hypoglycemia" were utilized to search for both abstracts and full articles in English. Overall, 39 reviews, preclinical studies and clinical studies were collected for use in this review. Fifteen of these studies were explicitly discussed in this review whereas the remaining articles were simply referenced. Two clinical trials currently being conducted were also described.

\section{Discussion}

Preclinical Studies and Carbohydrate Restriction

Cachexia, also known as wasting syndrome, is frequently reported in cancer patients. In 
response, regulatory starvation mechanisms promote plasma ketone body levels, which have been observed to reduce rates of glycolysis and gluconeogenesis [22]. It has been suggested that cancerous cells have an intrinsic dependence on glycolysis. The induction of ketosis (the production of ketone bodies), may reduce malignant cell growth [23-26]. In a 1979 study, Magee, et al. studied 36 C57BL/6 mice in two different environments; one in which half the mice were fed water and sucrose (Group 1), and another where mice were only fed water and polyunsaturated, blended vegetable oil (Group 2). All mice had melanoma cells implanted in their tails, and after two weeks of incubation in their respective environments, two independent observers determined malignant cell growth. This study demonstrated that an increased saturation of $\mathrm{BHB}$, which was observed in the oil-fed mice, hindered the proliferation of malignant cells in culture. The lack of available glucose in Group 2 induced a hypoglycemic state. It was inferred that since ketone bodies were unable to be metabolized, malignant cell growth was greatly dampened. Given the effect of ketone bodies on generalized malignant cell growth, a potential link between this carbohydrate-fasted state and cancer treatment was postulated [19].

Critics of the previous study argued that perhaps a lack of carbohydrates in the diet did not contribute to the inhibition of malignant cell growth, but instead this inhibition was due to fewer dietary calories administered throughout the study. A 2003 study by Seyfried, et al. attempted to determine the effects of calorie restriction on malignant brain cancers while controlling for carbohydrate restriction. Mice were implanted with a CT-2A malignant astrocytoma and placed in four treatment categories: a standard, unrestricted calorie diet (SDUR); a ketogenic, unrestricted calorie diet (KD-UR); a standard diet, restricted to $40 \%$ of the SD-UR calories (SD-R); or a ketogenic diet, restricted to $40 \%$ of the SD-UR (KD-R). Body weights, tumor weights, and BHB concentrations were measured two weeks after implantation. Tumor growth was rapid in both of the unrestricted diet groups (SD-UR and KD-UR). However, in the restricted diet cohorts, malignant growth was significantly impaired. Overall, an 80\% reduction in tumor growth was correlated with caloric restriction, with little deviation arriving from the origin of calories [27]. This study suggested that the amount of calories and not necessarily their origin was more integral for malignant growth. However, further studies had yet to establish a calorically restricted ketogenic diet as a potential aid in the management of cancer.

Zhou, et al. recently introduced $\mathrm{KetoCal}^{\circledR}$, a ketogenic diet that is no different from previously discussed KDs except that KetoCal ${ }^{\circledR}$ had become the standardized KD treatment for epileptic patients. The KetoCal ${ }^{\circledR}$ diet was investigated as a potential therapy to minimize the vascularity and malignancy of intracranial neoplasms, specifically astrocytomas [24]. In their study, mice were categorized into calorically unrestricted and restricted KetoCal ${ }^{\circledR}$ diets. This cohort was compared to a control group receiving a standard, high-carbohydrate/low-fat diet. Whereas both the unrestricted and restricted KetoCal ${ }^{\circledR}$ diets slowed tumor growth, decreased vascularity, and increased mouse survival relative to the control group, the restricted KetoCal ${ }^{\circledR}$ diet was associated with the best survival overall. A variety of metabolism-related metrics were measured. Precursors, such as plasma glucose level and glutamate breakdown, were significantly lowered in the restricted KetoCal ${ }^{\circledR}$ diet group versus the restricted standard, highcarbohydrate diet group (Figures 1,2). On the molecular biological scale, gene expression for mitochondrial enzymes, such as BHB dehydrogenase and succinyl-CoA: 3-ketoacid CoA transferase, proteins that stimulate metabolism and growth, had diminished. Tumor density had also decreased significantly. This implied that the abundance of ketone bodies were effective in slowing brain metabolism, specifically in neoplastic cells. Marsh, et al. later studied the effects of a metabolism-inhibiting drug in conjunction with the KD on malignant gliomas [28]. The glucose molecule exposed to a hydroxyl group, known as 2-deoxy-d-glucose (2-DG), is a competitive inhibitor of glucose in glycolysis. Low-dose 2-DG ( $25 \mathrm{mg} / \mathrm{kg}$ ) has been shown to produce similar calorie and energy restrictions. A restricted ketogenic diet (KD-R) and 2-DG was implemented in mice implanted with malignant gliomas and the results were compared 


\section{Cureus}

with the control groups of a SD-UR and KD-R with and without 2-DG administration. After treatment, tumor weights were significantly lower in the KD-R and the KD-R+2-DG versus the control cohorts: $48 \%$ and $80 \%$, respectively. Overall tumor size was smallest in the KD-R+2-DG, implying that a simultaneous KD-R+2-DG therapy may have potential to shrink tumors [28].

\section{Figure 1}

\section{Ketogenic Diet: Metabolism}

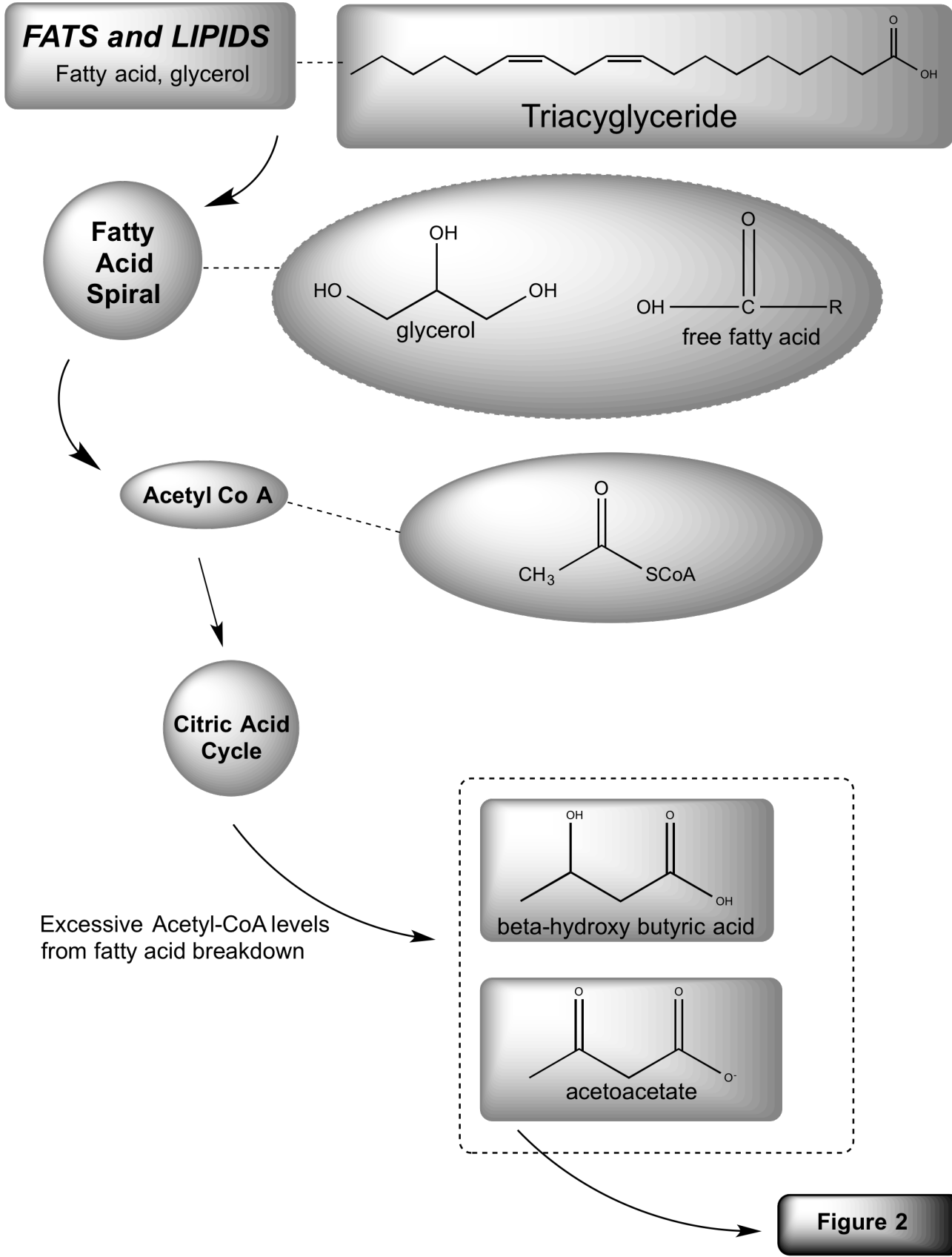

FIGURE 1: Ketogenic diet: metabolism 


\section{Cureus}

\section{Figure 2}

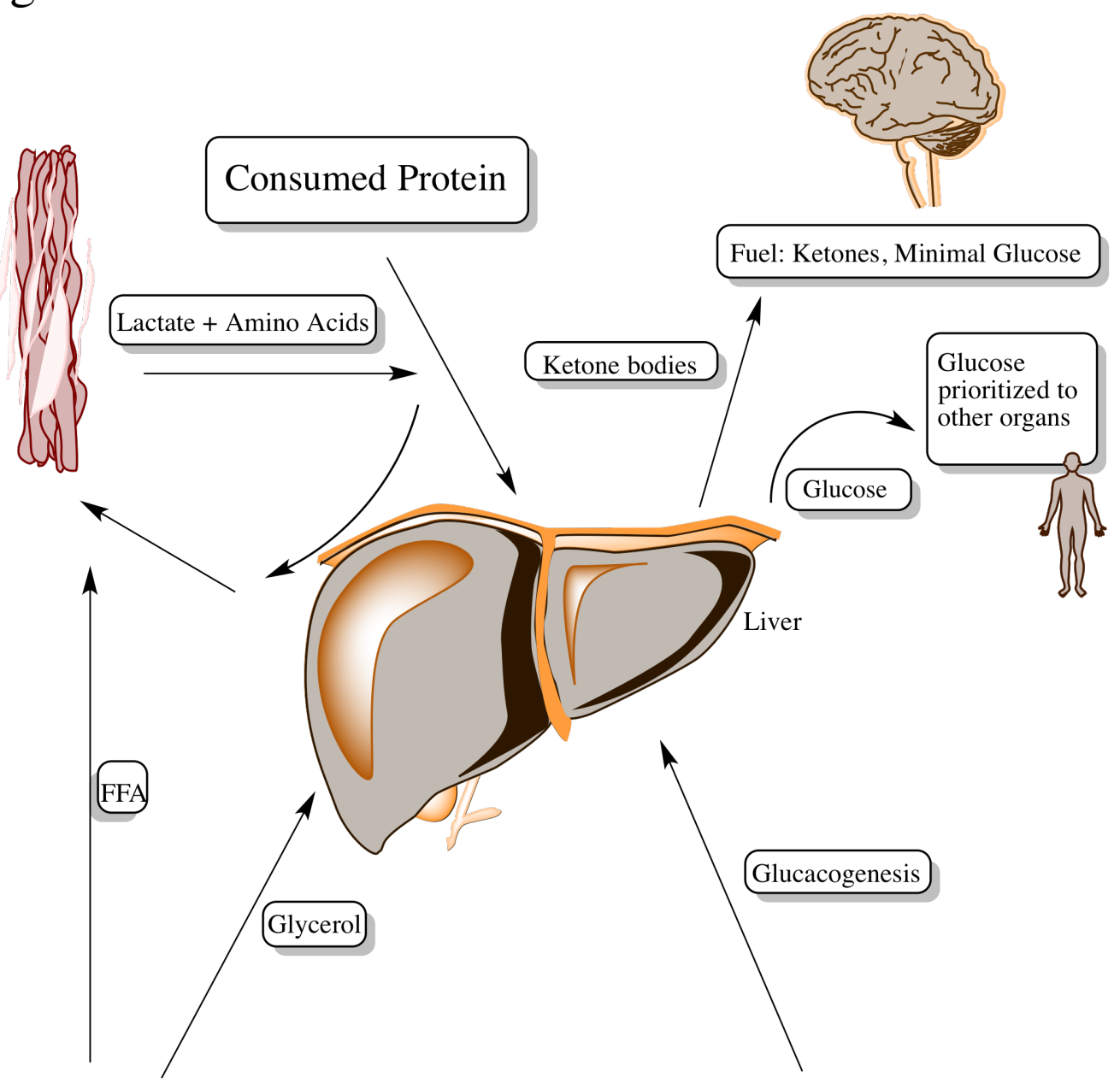

Consumed Fatty Acid, (excessive amount ketogenic diet)

\section{Energy Allocation during Ketogenic Diet Administration}

\section{FIGURE 2: Energy allocation during ketogenic diet}

\section{administration}

Studies have shown that a KD-R can be a beneficial adjuvant treatment for malignant astrocytomas; however, few studies have been able to demonstrate a better prognosis in GBM cohorts. In 2010, Stafford, et al. induced a hypoglycemic state in mice and attempted to determine the effects on a GL261 mouse glioma, an experimental model of a GBM. One cohort of mice was fed a KD-UR while another received an SD-UR. After the incubation period passed, the KD-UR cohort was correlated with better survival and slower neoplastic proliferation rate. Similar to Zhou, et al., the KD-UR treatment was associated with diminished metabolism and tumor growth on a molecular biological scale. Diminished amounts of mitochondrial enzymes and low levels of reactive oxygen species (ROS), compounds associated with metabolism 
promotion, were observed implying that a KD-UR may inhibit glucose metabolism via inhibition of glycolysis. Genes that are expressed in elevated levels during metabolism were also affected. Genes encoding for enzymes commonly present in saturated levels during glycolysis, such as cyclooxygenase 2, glutathione peroxidases 3 and 7, and peroxiredoxin 4, were sparse. This was another indication that a KD-UR could potentially stagnate tumor growth by inhibiting metabolic components. In addition to increased survival rates among the KD-UR mice, these observations suggest that a KD-UR, although not calorically limited, may still aid in the treatment of intracranial neoplasms [29]. In 2011, Maurer, et al. used a similar method of classification of mouse cohorts and were able to observe elevated levels of 3-hydroxybutyrate dehydrogenase 1 and 2 (BDH1 and 2), 3-oxoacid-CoA transferase 1 (OXCT1), and acetyl-CoA acetyltransferase 1 (ACAT1) - common ketone body metabolizing agents. Counterpart glycolytic agents were absent and glioblastoma growth stagnated. Plasma glucose levels remained low and overall results were consistent with previous studies on the ketogenic diet, supporting the efficacy of a KD-UR in malignant intracranial tumor treatment [30]. A final implementation of the popular pediatric epilepsy treatment, $\mathrm{KetoCal}^{\circledR}$, was studied in conjunction with a radiation ( 2 x 4 Gy) treatment in malignant gliomas. As expected, BHB levels were elevated in the KetoCal ${ }^{\circledR}$ rat cohort $(p=0.0173)$ and the bioluminescent marker reacting with the tumor cells in the rats fell below detection $(p<0.0001)$. Furthermore, mean survival in this group was five days longer than in the control rats receiving a standard diet. These results suggested that the ketogenic diet significantly enhanced the anti-tumor effects of radiation treatment [24, 2730]. These studies portrayed the efficacy of the ketogenic diet as a potential adjuvant therapy in addition to traditional treatment of GBMs, effectively building the foundation for clinical trials.

\section{Clinical Effectiveness of a KD in Anaplastic Astrocytoma}

Although the ketogenic diet has been a standard treatment for epileptic patients for decades, only recently has the KD been utilized in human subjects with cancer. Given the significant results of tumor shrinkage and improved survival in mouse models, it was hypothesized that a KD-UR may have a survival impact on cerebral cancer patients [31]. In 1995, Nebeling, et al. induced ketosis in pediatric astrocytoma patients by feeding them a KD consisting of $60 \%$ medium-chain triglyceride (MCT) oil, $20 \%$ protein, $10 \%$ carbohydrate, and $10 \%$ dietary fats. In an attempt to emulate the results of previous preclinical studies, tumor growth, glucose uptake, plasma glucose levels, and ketone body levels were monitored. After seven days of KD initiation, plasma ketone body levels increased 20 -fold and blood glucose levels dropped significantly. Through PET scan analysis, the tumors were also observed to have reduced glucose uptake by $21.8 \%$. This pioneer study concluded that a ketogenic diet was safe for humans, and in fact supported previous findings, and stated that a KD could potentially supplement cancer treatment [32]. Since this study did not have access to long-term patient data, a significant limitation was the omission of progression-free and overall survival data of patients treated with a KD. However, given the KD's previously observed effectiveness, later studies sought to determine the outcome of patients initially treated with a KD.

\section{Clinical Presence of Elevated Levels of Serum-Glucose and GBM}

In 2008, a retrospective study by McGirt, et al. was conducted analyzing a hyperglycemic state and its effect on the prognosis of GBM patients [33]. A hyperglycemic state is the opposite of what a KD perpetuates, and through isolating the effects of glucose levels on the tumor, it was determined that chronic hyperglycemic states are independently associated with diminished survival following a resection, regardless of steroid usage. A cohort of 297 GBM patients who had undergone surgical tumor resection was studied. Persistent hyperglycemia was defined by at least three observations of plasma-glucose levels surpassing $180 \mathrm{mg} / \mathrm{dl}$ within one to three months postoperatively. Variables, such as older age $(\mathrm{p}=0.001)$, lower Karnofsky Performance Scale score $(\mathrm{p}=0.001)$, higher tumor grade $(\mathrm{p}=0.001)$, primary versus secondary resection 
( $\mathrm{p}=0.008$ ), temozolomide administration $(\mathrm{p}=0.007)$, and continued outpatient dexamethasone therapy in addition to elevated levels of hyperglycemia were associated with diminished overall survival. Following initial GBM resection, hyperglycemic patients were observed to have a significantly reduced survival ( 5 vs. 11 months, $\mathrm{p}<0.05$ ). This observation was consistent with the secondary resection cohort, which also demonstrated a reduced survival in hyperglycemic patients ( 5 vs. 9 months, $p<0.05$ ). Overall, even GBM patients without recurrent tumors experienced a significantly worse prognosis with high glucose levels ( 8 vs. 13 months, $\mathrm{p}<0.05$ ) [31]. In a similar study by Derr, et al., 191 newly diagnosed GBM patients were divided into four cohorts of mean plasma glucose levels according to measurements taken weekly during radiation treatment. The four quartiles of plasma glucose in these patients were defined as follows: quartile one (<94 mg/dL), quartile two (94 to $109 \mathrm{mg} / \mathrm{dL}$ ), quartile three (110 to 137 $\mathrm{mg} / \mathrm{dL}$ ) and quartile four (>137 mg/dL). Median survival among these groups was 14.5, 11.6, 11.6, and 9.1 months, respectively. After adjusting for intergroup differences, such as age, extent of resection, and adjuvant therapies, significantly reduced survival in patients with increased levels of plasma glucose was observed $(p=0.041)$ [34].

Another experiment to test the effects on hyperglycemia on lower grade gliomas with a cohort of 189 patients revealed a correlation between elevated plasma glucose levels and increased malignancy and likelihood of recurrence, with diminished survival [35]. These studies demonstrated that elevated glucose levels may be detrimental to overall survival, indicating that a treatment that may inhibit this may have potential in managing malignant growth. Further studies inferred that since preventing hyperglycemia may aid in the treatment of lowgrade gliomas, this practice might also have a place in the treatment of GBMs.

\section{Clinical Studies of the KD in Glioblastoma Patients}

A case report in 2010 discussed a 65-year-old female being admitted with symptoms of memory loss, chronic headaches and nausea. With a family history of cancer and the given symptoms, she was diagnosed with a multi-centric GBM tumor. A KD-R was administered. Following the KD-R, treatment of surgery, radiation and chemotherapy was given. After two months of treatment, a MRI scan revealed that no residual tumor cells were present [36]. This success was rare and sparked the interest of many in the KD-UR, as it was the only novel aspect of the treatment. Following this report, a pilot study was conducted in 16 patients presenting with advanced stage lung, liver or bone cancers. A KD was administered to these patients, but due to a variety of reasons, such as an unpalatable nature of $\mathrm{KD}$ and death, only five subjects were able to complete the three-month intervention. These patients reported less insomnia and improved overall mood, two important quality of life parameters [37]. Another study of the KD and its efficacy as a glioblastoma treatment was conducted by Champ, et al. in which GBM patients were retrospectively analyzed from August 2010 to April 2013. Serum glucose and plasma ketone levels were monitored along with overall toxicity (Common Terminology Criteria for Adverse Events Grades 1-5; 1 being mild and 5 being death) and dexamethasone dosage. Six of 53 patients diagnosed with a GBM were fed a KD-UR while the other 47 were fed a standard, carbohydrate-rich diet. After monitoring the patients for 14 months, four of the six KD-R patients were still alive with no signs of chronic hypoglycemia, fatigue, or other potential sideeffects. Mean plasma glucose levels were measured, and the standard diet (SD) patients were found to have measurements of $122 \mathrm{mg} / \mathrm{dl}$ versus $84 \mathrm{mg} / \mathrm{dl}$ in the ketogenic diet fed patients. Serum levels were monitored and glucose levels were found to have dropped precipitously whereas ketone body presence rose. The KD-UR was well tolerated throughout the study with nominal side effects, such as weight loss (potentially due to a 30\% reduction of calories), and Grades I and II fatigue. KD-R cohort recurrence was observed at a median time of 10.3 months post-diagnosis. Most patients responded well to the KD-UR, with one patient recurring at seven months and another not showing any signs of recurrence 12 months after initial treatment. One of the other four patients died at six months due to a more aggressive, multifocal GBM. Overall, the KD was well tolerated and reduced serum glucose levels significantly without any 


\section{Cureus}

reported symptoms of chronic hypoglycemia. It was suggested that since a hypoglycemic state is detrimental to tumor growth, KD could be an option prior to more standard treatments, such as surgery and chemoradiation [38].

Many studies have suggested that elevated plasma glucose levels are correlated with accelerated tumor growth and poor progression-free and overall survival. Some have demonstrated that a KD and KD-UR are both effective in aiding the management of malignant growth, where a KD-UR had the highest efficacy [28, 31, 33, 39]. The success of these studies prompted further research into the aspects of the KD that made it effective, such as an induced hypoglycemic state and the inhibition of glutamate to glutamine conversion [38]. Hyperglycemia, which is inhibited by a KD, was shown to amplify systematic symptoms and increase tumor density, hindering prognosis significantly [32, 35]. These results promoted the $\mathrm{KD}$ as a potential supplement to the standard treatment of GBM; however, the translation to human subjects was unknown. Later clinical studies demonstrated that the $\mathrm{KD}$ is a safe and tolerable adjuvant therapy [38].

At the time of this review, there are two ongoing clinical trials set to be completed by 2016 studying the efficacy of a KD in GBM patients: a Phase I/II and a Phase II trial. In the Phase I/II trial, GBM patients will be administered a traditional 4:1 ratio of fat to carbohydrate KD while being treated chemoradiation for six weeks. Monthly chemotherapy will be given afterwards. Patients will have an initial MRI scan, weekly blood tests to monitor ketone levels and a final MRI test [40]. In the Phase II trial, recurrent GBM will be treated with a similar KD as the previous trial, along with chemoradiation. Following the treatment, bevacizumab may be administered [41]. Both studies aim to determine the tolerability and safety of a KD, along with its efficacy as a tumor-shrinking agent. Preclinical and clinical studies have both been able to suggest the effectiveness and tolerability of the $\mathrm{KD}$ and the $\mathrm{KD}$-UR; however, the precise success of tumor shrinkage exhibited in the preclinical trials has not been explicitly carried over into the clinic. It is difficult to draw conclusions based on these studies given their lack of large cohorts-the largest being a group of six patients being treated with a KD [38]. Moreover, the exact scientific mechanisms of how the KD works are still unclear. Studies dissecting the aspects of a $\mathrm{KD}$ and finding the exact attribute of a KD that provides benefits are warranted. Furthermore, larger cohort studies to show a more conclusive and statistically significant improvement of KD therapy on GBM patient prognosis are needed. Table 1 is a summary of the most significant studies implementing the ketogenic diet in glioma patients in the animal cohort. Table 2 analyzes the same variables in the human cohort. Both tables are organized based on cohort size and levels of evidence (I - VII).

\begin{tabular}{|l|l|l|} 
Authors & Summary of Study & $\begin{array}{l}\text { Level of } \\
\text { Evidence }\end{array}$ \\
\hline & $\begin{array}{l}\text { Mice were implanted with } \\
\text { malignant gliomas, given } 2 \mathrm{x}\end{array}$ \\
\hline $\begin{array}{ll}\text { Adelwahab } \\
\text { MG, et al. }\end{array}$ & $\begin{array}{l}\text { administered either a SD or a a } \\
\text { adiation and }\end{array}$ \\
\hline 31$]$ & $\begin{array}{l}\text { KD; tumor growth was } \\
\text { monitored with in vivo } \\
\text { imaging }\end{array}$ \\
\hline
\end{tabular}

\section{Cohort Conclusions}

Animals fed KD had elevated levels of $\beta$ hydroxybutyrate $(p=0.0173)$ and an increased median survival of approximately 5 days relative to animals maintained on SD. KD plus radiation treatment were more than additive, and in 9 of 11 irradiated animals maintained on KD, the bioluminescent signal from the tumor cells diminished below the level of detection $(p<0.0001)$.

Tumor weights were about $48 \%$ and $80 \%$ lower in the KD-R and in the KD-R+2-DG groups, 


\section{Cureus}

\begin{tabular}{|c|c|c|c|c|}
\hline $\begin{array}{l}\text { Marsh J, et } \\
\text { al. [28] }\end{array}$ & $\begin{array}{l}\text { Mice were implanted with } \\
\text { malignant astrocytomas and } \\
\text { administered SD or KD; } \\
\text { within these groups, half } \\
\text { were given 2-deoxy-D- } \\
\text { glucose }\end{array}$ & 1 & 11 & $\begin{array}{l}\text { respectively, than in the SD-UR group. Mouse } \\
\text { health and vitality was better in the KD-R group } \\
\text { than in the KD-R+2-DG group. Astrocytoma } \\
\text { growth was reduced more in the KD-R mouse } \\
\text { group supplemented with 2-DG than in the mouse } \\
\text { groups receiving either dietary restriction or 2-DG } \\
\text { alone, indicating a synergistic interaction between } \\
\text { the drug and the diet. }\end{array}$ \\
\hline $\begin{array}{l}\text { Maurer } \\
\text { GD, et al. } \\
{[30]}\end{array}$ & $\begin{array}{l}\text { Rats were implanted with a } \\
\text { glioma and administered SD } \\
\text { or KD }\end{array}$ & 2 & 24 & $\begin{array}{l}\text { In vivo, the ketogenic diet led to a robust increase } \\
\text { of blood 3-hydroxybutyrate, but did not alter } \\
\text { blood glucose levels or improve survival. }\end{array}$ \\
\hline $\begin{array}{l}\text { Mukherjee } \\
\text { P, et al. } \\
{[15]}\end{array}$ & $\begin{array}{l}\text { Mice were implanted with a } \\
\text { glioma (U87-MG), an } \\
\text { astrocytoma (CT-2A), or an } \\
\text { ependymoma (EPEN) and } \\
\text { were administered calorie- } \\
\text { restricted diets }\end{array}$ & 1 & 83 & $\begin{array}{l}\text { The weights of the CT-2A, EPEN, and U87-MG } \\
\text { tumors were approximately } 80 \%, 63 \% \text {, and } 60 \% \\
\text { less with a calorie-restricted diet than standard, } \\
\text { caloric surplus diet. }\end{array}$ \\
\hline $\begin{array}{l}\text { Seyfried } \\
\text { TN, et al. } \\
{[27]}\end{array}$ & $\begin{array}{l}\text { Mice were implanted with a } \\
\text { glioma and were fed either a } \\
\text { standard diet unrestricted } \\
\text { (SD-UR), a ketogenic diet } \\
\text { unrestricted (KD-UR), the SD } \\
\text { restricted to } 40 \% \text { (SD-R), or } \\
\text { the KD restricted to } 40 \% \text { of } \\
\text { the control standard diet } \\
\text { (KD-R). }\end{array}$ & 1 & 33 & $\begin{array}{l}\text { CT-2A growth was rapid in both the SD-UR and } \\
\text { KD-UR groups, but was significantly reduced in } \\
\text { both the SD-R and KD-R groups by about } 80 \% \text {. }\end{array}$ \\
\hline $\begin{array}{l}\text { Zhou W, et } \\
\text { al. [24] }\end{array}$ & $\begin{array}{l}\text { Adult mice were implanted } \\
\text { orthotopically with the } \\
\text { malignant brain tumors and } \\
\text { KetoCal was administered to } \\
\text { the mice in either } \\
\text { unrestricted amounts or in } \\
\text { restricted amounts to reduce } \\
\text { total caloric intake }\end{array}$ & 1 & 34 & $\begin{array}{l}\text { KetoCal } \circledast \text { administered in restricted amounts } \\
\text { significantly decreased the intracerebral growth of } \\
\text { the CT-2A and U87-MG tumors by about } 65 \% \text { and } \\
35 \% \text {, respectively. Tumor microvessel density } \\
\text { was less in the calorically restricted KetoCal } ® \\
\text { groups than in the calorically unrestricted control } \\
\text { groups. Moreover, gene expression for the } \\
\text { mitochondrial enzymes, } \beta \text {-hydroxybutyrate } \\
\text { dehydrogenase and succinyl-CoA: 3-ketoacid CoA } \\
\text { transferase, was lower in the tumors than in the } \\
\text { contralateral normal brain. }\end{array}$ \\
\hline
\end{tabular}

\section{TABLE 1: Animal studies of calorie restricted or ketogenic diet with diagnosis of glioma}

\begin{tabular}{|c|c|c|c|c|}
\hline Authors & Summary of Study & $\begin{array}{l}\text { Level of } \\
\text { Evidence }\end{array}$ & Cohort & Conclusions \\
\hline & Retrospective analysis of patients with a & & & $\begin{array}{l}\text { Persistent outpatient } \\
\text { hyperglycemia (relative risk, }\end{array}$ \\
\hline
\end{tabular}




\section{Cureus}

diagnosis of a high-grade hemispheric

glioma and persistent elevated levels of

McGirt M, et al.

[33]

plasma glucose, defined by higher than

$180 \mathrm{mg} / \mathrm{dl}$ at least three times

2

postoperatively within 3 months of

surgery and its association with survival was studied.

Retrospective analysis of patients with a diagnosis of a low-grade hemispheric glioma and persistent elevated levels of

Chaichana KL, et plasma glucose, defined by higher than al. [35]

postoperatively within 3 months of surgery and its association with survival was studied.

Retrospective analysis of patients

Champ CE, et al. between 2010-2013 who underwent KD [38] therapy along with the standard treatment
Retrospective analysis of patients with GBMs and their outcomes (overall survival) based on postoperative

Derr RL, et al. [34] glycemic levels. Patients were divided into quartiles: quartile one ( $<94 \mathrm{mg} / \mathrm{dL})$, quartile two (94 to $109 \mathrm{mg} / \mathrm{dL}$ ), quartile three (110 to $137 \mathrm{mg} / \mathrm{dL}$ ), and quartile four (> $137 \mathrm{mg} / \mathrm{dL})$.

Prospective study administering KD to patients with advanced metastatic

Schmidt M, et al. [37] cancer, hoping to determine feasibility and effectiveness of KD as an adjuvant treatment to standard of care.

Prospective study administering

Michelakis MD, et al. [21] dichloroacetate (DCA) to mitochondrial cell lines of patients diagnosed with
Median survival times for patients in quartiles one, two, three, and four were 14.5, 11.6, 11.6, and 9.1 months, respectively.

Patients reported less insomnia and better overall mood; cholesterol and blood lipid levels did not significantly change, no severe side-effects observed.

DCA depolarized mitochondria, increased mitochondrial reactive oxygen species, and induced apoptosis in GBM cells, as well as in putative GBM stem cells, both in vitro 


\section{Cureus}

GBM.

and in vivo. DCA sufficient to

inhibit the target enzyme of DCA, pyruvate dehydrogenase kinase II, which was highly expressed in all glioblastomas.

TABLE 2: Human studies of calorie-restricted or ketogenic diet with diagnosis of malignant glioma

\section{Conclusions}

Preclinical studies have established that a ketogenic diet (KD) is correlated with improved prognosis in high-grade glioma mouse models. These findings were later applied to clinical studies, in which hyperglycemic individuals with GBMs generally had poorer survival rates than those with lower blood glucose levels. Recent clinical findings have demonstrated that induced hypoglycemia and a ketogenic diet are tolerable and can potentially be an adjuvant to standard treatments, such as surgery and chemoradiation. Other findings have advocated for KD as an malignant cell growth inhibitor and indicate that further studies including the ongoing clinical trials analyzing larger cohorts of GBM patients treated with a KD are needed to determine the breadth of impact a KD may have on GBM treatment.

\section{Additional Information}

\section{Disclosures}

Conflicts of interest: In compliance with the ICMJE uniform disclosure form, all authors declare the following: Payment/services info: All authors have declared that no financial support was received from any organization for the submitted work. Financial relationships: All authors have declared that they have no financial relationships at present or within the previous three years with any organizations that might have an interest in the submitted work. Other relationships: All authors have declared that there are no other relationships or activities that could appear to have influenced the submitted work.

\section{References}

1. Dolecek TA, Propp JM, Stroup NE, Kruchko C: CBTRUS statistical report: primary brain and central nervous system tumors diagnosed in the United States in 2005-2009. Neuro Oncol. 2012, 14:v1-49. 10.1093/neuonc/nos218

2. Krex D, Klink B, Hartmann C, et al.: Long-term survival with glioblastoma multiforme . Brain. 2007, 130:2596-2606.

3. Johnson DR, O'Neill BP: Glioblastoma survival in the United States before and during the temozolomide era. J Neurooncol. 2012, 107:359-364. 10.1007/s11060-011-0749-4

4. Yung WK, Prados MD, Yaya-Tur R, et al.: Multicenter phase II trial of temozolomide in patients with anaplastic astrocytoma or anaplastic oligoastrocytoma at first relapse. Temodal Brain Tumor Group. J Clin Oncol. 1999, 17:2762-2771.

5. Hou LC, Veeravagu A, Hsu AR, Tse VC: Recurrent glioblastoma multiforme: a review of natural history and management options. Neurosurg Focus. 2006, 20:E5.

6. Stupp R, Hegi ME, Mason WP, van den Bent MJ, Taphoorn MJ, Janzer RC, Ludwin SK, Allgeier A, Fisher B, Belanger K, Hau P, Brandes AA, Gijtenbeek J, Marosi C, Vecht CJ, Mokhtari K, Wesseling P, Villa S, Eisenhauer E, Gorlia T, Weller M, Lacombe D, Cairncross JG, Mirimanoff RO: Effects of radiotherapy with concomitant and adjuvant temozolomide versus radiotherapy alone on survival in glioblastoma in a randomised phase III study: 5-year analysis of the EORTC-NCIC trial. Lancet Oncol . 2009, 10:459-466.

7. Chiu WT, Shen SC, Chow JM, Lin CW, Shia LT, Chen YC: Contribution of reactive oxygen 
species to migration/invasion of human glioblastoma cells U87 via ERK-dependent COX2/PGE 2 activation. Neurobiol Dis. 2010, 37:118-129. 10.1016/j.nbd.2009.09.015

8. Xu RH, Pelicano H, Zhou Y, et al.: Inhibition of glycolysis in cancer cells: A novel strategy to overcome drug resistance associated with mitochondrial respiratory defect and hypoxia. Cancer Res. 2005, 65:613-621.

9. Maroon J, Bost J, Amos A, Zuccoli G: Restricted calorie ketogenic diet for the treatment of glioblastoma multiforme. J Child Neurol. 2013, 28:1002-1008. 10.1177/0883073813488670

10. Atif F, Yousuf S, Stein DG: Anti-tumor effects of progesterone in human glioblastoma multiforme: Role of PI3K/Akt/mTOR signaling. J Steroid Biochem Mol Biol. 2015. 2015, 146:62-73. 10.1016/j.jsbmb.2014.04.007

11. Nei M, Ngo L, Sirven JI, Sperling MR: Ketogenic diet in adolescents and adults with epilepsy. Seizure. 2014, 23:439-42. 10.1016/j.seizure.2014.02.015

12. Li HF, Zou Y, Ding G: Therapeutic Success of the Ketogenic Diet as a Treatment Option for Epilepsy: a Meta-analysis. Iran J Pediatr. 2013, 23:613-620.

13. Selter JH, Turner Z, Doerrer SC, Kossoff EH: Dietary and medication adjustments to improve seizure control in patients treated with the ketogenic diet. J Child Neurol. 2015, 30:53-7. 10.1177/0883073814535498

14. Tripathi M, Kaul B: Treatment options for epilepsy in adults. J Assoc Physicians India. 2013, 61:15-18.

15. Mukherjee P, Abate LE, Seyfried TN: Antiangiogenic and proapoptotic effects of dietary restriction on experimental mouse and human brain tumors. Clin Cancer Res. 2004, 10:56225629.

16. Warburg O: On the origin of cancer cells . Science. 1956, 10:309-314.

17. Pelicano H, Martin DS, Xu RH, Huang P: Glycolysis inhibition for anticancer treatment. Oncogene. 2006, 25:4633-4646.

18. Scheck AC, Abdelwahab MG, Fenton KE, Stafford P: The ketogenic diet for the treatment of glioma: insights from genetic profiling. Epilepsy Res. 2012, 100:327-337. 10.1016/j.eplepsyres.2011.09.022

19. Magee BA, Potezny N, Rofe AM, Conyers RA: The inhibition of malignant cell growth by ketone bodies. Aust J Exp Biol Med Sci. 1979, 57:529-539.

20. Patel M, Vogelbaum MA, Barnett GH, Jalali R, Ahluwalia MS: Molecular targeted therapy in recurrent glioblastoma: current challenges and future directions. Expert Opin Investig Drugs. 2012, 21:1247-1266. 10.1517/13543784.2012.703177

21. Michelakis ED, Sutendra G, Dromparis P, et al.: Metabolic modulation of glioblastoma with dichloroacetate. Sci Transl Med. 2010, 2:31ra34. 10.1126/scitranslmed.3000677

22. Cahill GF: Protein and amino acid metabolism in man . Circ Res. 1976, 38:I109-114.

23. Conyers RA, Need AG, Durbridge T, Harvey ND, Potezny N, Rofe AM: Cancer, ketosis and parenteral nutrition. Med J Aust. 1979, 1:398-399.

24. Zhou W, Mukherjee P, Kiebish MA, Markis WT, Mantis JG, Seyfried TN: The calorically restricted ketogenic diet, an effective alternative therapy for malignant brain cancer. Nutr Metab (Lond). 2007, 4:5.

25. Conyers RA, Need AG, Rofe AM, Potezny N, Kimber RJ: Nutrition and cancer. Br Med J. 1979, $1: 1146$.

26. Krebs HA: Otto Heinrich Warburg: 1883-1970. Biogr Mem Fellows R Soc. 1972, 18:629-699.

27. Seyfried TN, Sanderson TM, El-Abbadi MM, McGowan R, Mukherjee P: Role of glucose and ketone bodies in the metabolic control of experimental brain cancer. Br J Cancer. 2003, 89:1375-1382.

28. Marsh J, Mukherjee P: Seyfried TN: Drug/diet synergy for managing malignant astrocytoma in mice: 2-deoxy-D-glucose and the restricted ketogenic diet. Nutr Metab (Lond). 2008, 5:33. 10.1186/1743-7075-5-33

29. Stafford P, Abdelwahab MG, Kim dY, Preul MC, Rho JM, Scheck AC: The ketogenic diet reverses gene expression patterns and reduces reactive oxygen species levels when used as an adjuvant therapy for glioma. Nutr Metab (Lond). 2010, 7:74. 10.1186/1743-7075-7-74

30. Maurer GD, Brucker DP, Bähr O, et al.: Differential utilization of ketone bodies by neurons and glioma cell lines: a rationale for ketogenic diet as experimental glioma therapy. BMC Cancer. 2011, 11:315. 10.1186/1471-2407-11-315

31. Abdelwahab MG, Fenton KE, Preul MC, et al.: The ketogenic diet is an effective adjuvant to radiation therapy for the treatment of malignant glioma. PLoS One. 2012, 7:e36197. 
32. Nebeling LC, Miraldi F, Shurin SB, Lerner E: Effects of a ketogenic diet on tumor metabolism and nutritional status in pediatric oncology patients: two case reports. J Am Coll Nutr. 1995, 14:202-208.

33. McGirt MJ, Chaichana KL, Gathinji M, et al.: Persistent outpatient hyperglycemia is independently associated with decreased survival after primary resection of malignant brain astrocytomas. Neurosurg. 2008, 63:286-291. 10.1227/01.NEU.0000315282.61035.48

34. Derr RL, Ye X, Islas MU, Desideri S, Saudek CD, Grossman SA: Association between hyperglycemia and survival in patients with newly diagnosed glioblastoma. J Clin Oncol. 2009, 27:1082-86. 10.1200/JCO.2008.19.1098

35. Chaichana KL, McGirt MJ, Woodworth GF, et al.: Persistent outpatient hyperglycemia is independently associated with survival, recurrence and malignant degeneration following surgery for hemispheric low grade gliomas. Neurol Res. 2010, 32:442-448.

10.1179/174313209X431101

36. Zuccoli G, Marcello N, Pisanello A, et al.: Metabolic management of glioblastoma multiforme using standard therapy together with a restricted ketogenic diet: Case Report. Nutr Metab (Lond). 2010, 7:33. 10.1186/1743-7075-7-33

37. Schmidt M, Pfetzer N, Schwab M, Strauss I, Kämmerer U: Effects of a ketogenic diet on the quality of life in 16 patients with advanced cancer: A pilot trial. Nutr Metab (Lond). 2011, 8:54. 10.1186/1743-7075-8-54

38. Champ CE, Palmer JD, Volek JS, et al.: Targeting metabolism with a ketogenic diet during the treatment of glioblastoma multiforme. J Neurooncol. 2014, 117:125-131. 10.1007/s11060-

014-1362-0

39. Seyfried TN, Marsh J, Shelton LM, Huysentruyt LC, Mukherjee P: Is the restricted ketogenic diet a viable alternative to the standard of care for managing malignant brain cancer?. Epilepsy Res. 2012, 100:310-326. 10.1016/j.eplepsyres.2011.06.017

40. St. Joseph's Hospital and Medical Center: Ketogenic Diet With Radiation and Chemotherapy for Newly Diagnosed Glioblastoma. ClinicalTrials.gov. 2013, Accessed: Accessed Oct 23, 2014: https://clinicaltrials.gov/ct2/show/NCT02046187.

41. Mid-Atlantic Epilepsy and Sleep Center, LLC: Ketogenic Diet as Adjunctive Treatment in Refractory/End-stage Glioblastoma Multiforme: A Pilot Study. ClinicalTrials.gov. 2013, Accessed: October 23, 2014: https://clinicaltrials.gov/ct2/show/NCT01865162. 